\title{
Neuronalinjury and roles of apoptosis and autophagy in a neonatal rat model of hypoxia-ischemia-induced periventricular leukomalacia
}

\author{
LIN QIAO, JIANHUA FU, XINDONG XUE, YONGYAN SHI, LI YAO, WANJIE HUANG, \\ JUN LI, DAN ZHANG, NA LIU, XIN TONG, YANNA DU and YUQING PAN \\ Department of Pediatrics, Shengjing Hospital of China Medical University, Shenyang, Liaoning 110004, P.R. China
}

Received October 26, 2016; Accepted June 20, 2017

DOI: $10.3892 / \mathrm{mmr} .2018 .8570$

\begin{abstract}
As research into periventricular leukomalacia (PVL) gradually increases, concerns are emerging about long-term neuron injury. The present study aimed to investigate neuronal injury and the relevant alterations in apoptosis and autophagy in a PVL model established previously. A rat model of hypoxia-ischemia-induced PVL was established. In the model group, Sprague-Dawley (SD) rats [postnatal day 3 (P3)] were subjected to right common carotid artery ligation followed by suturing and exposed to 6-8\% oxygen for $2 \mathrm{~h}$; in the control group, SD rats (P3) were subjected to right common carotid artery dissection followed by suturing, without ligation and hypoxic exposure. At 1, 3, 7 and 14 days following modeling, brain tissue samples were collected and stained with hematoxylin and eosin. Cellular apoptosis was detected by terminal deoxynucleotidyl transferase dUTP nick end labeling (TUNEL) assay and the protein and mRNA expression alterations of neuronal nuclei (NeuN), caspase-3 and Beclin 1 in the model group were detected by western blot analysis and reverse transcription-quantitative polymerase chain reaction (RT-qPCR) analyses. Compared with the control group, the protein and mRNA expression levels of $\mathrm{NeuN}$ (a marker of mature neurons) were markedly reduced, the number of positive cells was increased as detected by TUNEL, and the protein and mRNA expression levels of caspase- 3 and Beclin 1 were elevated in the model group. In the rat model of hypoxia-ischemia-induced PVL, oligodendrocyte injury and myelinization disorders were observed, in addition to neuron injury, a decrease in mature neurons and the co-presence of apoptosis and autophagy. However, apoptosis and autophagy
\end{abstract}

Correspondence to: Professor Xindong Xue, Department of Pediatrics, Shenjing Hospital of China Medical University, 36 Sanhao Street, Shenyang, Liaoning 110004, P.R. China

E-mail: xuexd@sj-hospital.org

Key words: hypoxia-ischemia, periventricular leukomalacia, neuron, apoptosis, autophagy exist in different phases: Apoptosis is involved in neuron injury, while autophagy is likely to have a protective role.

\section{Introduction}

White matter injury (WMI) is the most common type of brain injury and the major cause of sequelae of the nervous system in premature infants. In the USA, 60,000 extremely low birth weight infants are born every year (1) and the incidence rate of WMI in these infants is 50\% $(2,3)$. In addition, $~ 90 \%$ of WMI patients survive with sequelae to varying extents, of which $5-10 \%$ suffercerebral palsy and $50 \%$ experience behavior and/or attention deficit $(4,5)$. The majority of patients with serious sequelae demonstrate periventricular leukomalacia (PVL) as observed by magnetic resonance imaging (MRI), pathologically manifesting as local periventricular white matter necrosis, myelinization disorders, and gliocyte proliferation and microglial cell activation in adjacent white matter $(6,7)$.

The pathogenesis of WMI remains to be fully elucidated, although infection and hypoxia are recognized to be the primary inducing factors. Infection and hypoxia may lead to the release of glutamates, oxygen-derived free radicals and inflammatory cytokines, and thus activate microglial cells. Microglial cells may further release glutamates, oxygen-derived free radicals and inflammatory cytokines which may aggravate WMI; activated microglial cells may induce the death of oligodendrocyte precursor cells (OPCs) and astrocytes, which has been previously demonstrated $(8,9)$. Additionally, OPCs account for $90 \%$ of the total number of oligodendrocytes in the white matter of premature infants. Animal experiments have demonstrated that, based on the maturation-dependent vulnerability of oligodendrocytes, immature oligodendrocytes are more vulnerable during a specific window and are easily injured by glutamates, oxygen-derived free radicals and inflammatory cytokines, thus leading to apoptosis, necrosis and myelinization delay (10-12).

However, in the recent years, follow-ups of patients with PVL have demonstrated that these patients frequently exhibit such sequelae as all-round cognitive deficit, attention deficit, human communication disorders, language retardation and autism, which cannot be reasonably explained by WMI alone; 
these sequelae are closely associated with neuronal/axonal injury. With the development of neuropathology and imaging techniques, the focus of previous research has been directed to gray matter injury which has been long-neglected; a number of investigators have proposed that the pathological alteration sand neurodevelopmental outcomes of PVL may be not only limited to oligodendrocyte absence and myelinization disorders (13-15). MRI volumetric analysis indicates that the volume of gray matter in the cerebral cortex and subcortex is decreased in premature infants with PVL. Andiman et al (13) demonstrated by autopsy that the density of granular neurons of patients with PVL was markedly decreased compared with that of controls. In 2005, Volpe et al (14) from Harvard University (Cambridge, MA, USA) first proposed a concept of 'encephalopathy of prematurity (EP)', and they hypothesized that brain injury may not be accurately defined by WMI in premature infants and that the role of neuronal injury in brain injury was relevant. However, there are few preclinical studies into neuron injury in PVL. In the present study, neuronal alterations were investigated using a previously established hypoxia-induced PVL model (15) to clarify the impact of neuronal injury and its mechanism.

\section{Materials and methods}

Experimental animals and grouping. Ethical approval for the present study was provided by Shengjing Hospital of China Medical University Ethics Committee (Shenyang, China). A total of 80 Sprague-Dawley (SD) rats [postnatal day 3 (P3); weight, 10.2-12.1 g] were randomly assigned to the control group (normoxic exposure; $n=40$ ) or the model group (hypoxic exposure; $n=40$ ). The rats were raised under the following conditions: The temperature was $18-26^{\circ} \mathrm{C}$, the humidity was $47-70 \%$, day light for $10 \mathrm{~h}$ and dark for $14 \mathrm{~h}$, the food and water was supplied ad libitum. The body weight of rats was $11.5 \pm 1.3 \mathrm{~g}$ in the control group (male, 22) and $11.4 \pm 1.4 \mathrm{~g}$ in the model group (male, 21) and no statistical difference was identified between the weight and sex of the two groups. All rats were provided by the Experimental Animal Department, Shengjing Hospital of China Medical University. A hypoxia-ischemia-induced PVL rat model established previously by our research group was used and the modeling method was same as that for a hypoxia model established by Mizuno et al (16). The neonatal SD rats (P3) were weighed and numbered prior to surgery. Animals were anesthetized by isoflurane inhalation and fixed on the bench in a supine position. Following conventional disinfection, a $0.7-0.8 \mathrm{~cm}$ incision was made close to the tracheal midline under a dissecting microscope, and the right common carotid artery was exposed and ligated. Rats were postoperatively sent to the female rat cages with a room temperature and normoxic exposure for $2 \mathrm{~h}$ recovery, and were subsequently subjected to $2 \mathrm{~h}$ hypoxic exposure (6-8\% oxygen). Rats in the control group were only subjected to the dissection of the right common carotid artery, without ligation and hypoxic exposure. At 1, 3, 7 and 14 days post-surgery, the brain tissues of experimental rats were collected.

Hematoxylin and eosin $(H \& E)$ staining. The brain tissues were fixed with $4 \%$ paraformaldehyde for $48 \mathrm{~h}$ at room temperature, dehydrated with gradient ethanol (70\% ethanol for $2 \mathrm{~h}, 80 \%$ ethanol over night, $90 \%$ ethanol for $2 \mathrm{~h}, 100 \%$ I ethanol for $1 \mathrm{~h}, 100 \%$ II ethanol for $1 \mathrm{~h}$ ) vitrified with xylene, waxed, embedded with paraffin and conventionally sliced into $5-\mu \mathrm{m}$ tissue sections. Subsequently, the sections were stained with hematoxylin (ZLI-9609; Beijing Zhongshan Goldenbridge Biotechnology, Beijing, China) for $10 \mathrm{~min}$, washed with water for $15 \mathrm{~min}$, then eosin for $1 \mathrm{~min}$ (ZLI-9612; Beijing Zhongshan Goldenbridge Biotechnology), and washed with water for $10 \mathrm{sec}$. A total of six tissue sections from each group were selected randomly at various time-points, and were observed in 5 random fields under a light microscope at magnification, $\mathrm{x} 400$.

Terminal deoxynucleotidyl transferase dUTP nick end labeling (TUNEL) assay. The paraffin-embedded sections of brain tissues were conventionally dewaxed, treated with $50 \mu 10.1 \%$ Triton X-100 (prepared with $0.1 \%$ sodium citrate) and preserved at room temperature for $8 \mathrm{~min}$ for vitrification, washed with PBS for 5 min three times, treated with $3 \% \mathrm{H}_{2} \mathrm{O}_{2}$ at room temperature for $10 \mathrm{~min}$ to block peroxidase and washed three times with PBS for $5 \mathrm{~min}$. TUNEL reaction solution (cat. no. 11684817910; Roche Diagnostics GmbH, Mannheim, Germany) was prepared with enzyme solution and label solution at a dilution of 1:9 (freshly prepared on ice). The sections were wiped dry, $50 \mu 1$ TUNEL reaction solution was added, and sections were incubated in a humidified atmosphere away from light at $37^{\circ} \mathrm{C}$ for $60 \mathrm{~min}$, followed by washing with PBS for 5 min three times. Thereafter, the sections were wiped dry, $50 \mu 1$ converter-POD was added, and sections were incubated in a humidified atmosphere at $37^{\circ} \mathrm{C}$ for $30 \mathrm{~min}$, and washed with PBS for $5 \mathrm{~min}$ three times. The sections were removed and wiped dry, $50 \mu \mathrm{l}$ diaminobenzidine substrate (DAB; 1:20; zli-9017; OriGene Technologies, Inc.) was added at room temperature for $10 \mathrm{sec}$, and sections were rapidly placed into water to terminate the reaction when the color had just become deep. The sections were subsequently counterstained with hematoxylin at room temperature for 10 min, dehydrated with ethanol, vitrified with xylene and mounted. Instead of TUNEL reaction solution, PBS was used in the negative controls, and all procedures were same as the above. The cells with brown-yellow particles deposited in the cytoplasm were assessed to be positive cells. A total of six tissue sections from each group were selected randomly at various time-points, and they were observed in 5 random fields under a light microscope at magnification, x500.

Double-labeling immunofluorescence staining. The frozen sections $\left(10-\mu \mathrm{M}\right.$ thick; frozen at $\left.-80^{\circ} \mathrm{C}\right)$ of brain tissues were defrosted, fixed with acetone at $4^{\circ} \mathrm{C}$ for $30 \mathrm{~min}$, and washed with PBS for $5 \mathrm{~min}$ three times. Antigen retrieval was performed by boiling in antigen retrieval solution I at $100^{\circ} \mathrm{C}$ for $5 \mathrm{~min}$, and washed with PBS for $5 \mathrm{~min}$ three times. Sections were blocked with bovine serum albumin (BSA; cat. no. bs043a; Biosharp, Shandong, China) at room temperature for $1 \mathrm{~h}$. When the blocking solution was removed, the sections were incubated with primary antibodies against Beclin 1 (rabbit anti-rat antibody; 1:1,000; cat. no. ab55878) and neuronal nuclei (NeuN; mouse anti-rat antibody; 1:1,000; cat. no. ab104224) (both from Abcam, Cambridge, UK) at $4^{\circ} \mathrm{C}$ 
overnight. The following day, the sections were rewarmed at room temperature for $1 \mathrm{~h}$ and washed three times with PBS for $5 \mathrm{~min}$. Secondary antibodies [cat. no. ta130022; fluorescein isothiocyanate (FITC) conjugated goat anti-rabbit IgG, 1:64; and ta130012, Cy3-conjugated goat anti-mouse IgG, 1:50; OriGene Technologies, Inc.] were added and incubated away from light, at room temperature for $4 \mathrm{~h}$, followed by washing in the dark with PBS for 5 min three times. Nuclear staining was performed with DAPI (OriGene Technologies, Inc.) for $5 \mathrm{~min}$, and sections were washed in the dark with PBS for 5 min three times. Tissues were observed and photographed under a fluorescence microscope at magnification, x400 (MTC-600; Bio-Rad Laboratories, Inc., Hercules, CA, USA).

Western blotting. Brain tissues were collected from 3 rats in each group at each time-point. Tissues were added into radio immunoprecipitation assay lysis buffer (Beyotime Institute of Biotechnology, Haimen, China) at a dilution of 1:10, sheared into pieces using scissors, broken up with ultrasonication by $20 \mathrm{kHz}$ frequency on ice for $5 \mathrm{~min}$, and centrifuged at $4^{\circ} \mathrm{C}$ at $12,000 \mathrm{x} \mathrm{g}$ for $30 \mathrm{~min}$. The supernatant was removed to separate the proteins, which were transferred into a $0.5 \mathrm{ml}$ centrifuge tube. The protein concentration was measured using a bicinchoninic acid assay. The samples were adjusted to the same concentration, sample buffer was added, and samples were boiled for $5 \mathrm{~min}$ and preserved at $-80^{\circ} \mathrm{C}$. Proteins were mixed with $7.5 \%$ SDS-PAGE sample loading buffer and boiled for $5 \mathrm{~min}$ to achieve protein denaturation. The protein were loaded for $40 \mu \mathrm{g}$ per lane in a preset sequence, and the electrophoresis apparatus was connected to the power source $(80 \mathrm{~V}$; the current was directed towards the anode) and powered off when bromphenol blue was migrated to a position $0.5 \mathrm{~cm}$ away from the bottom of the separation gel. The gel glass plate was unloaded from the electrophoresis apparatus and washed clean with deionized water. Two filter papers and a polyvinylidenedifluoride (PVDF) membrane were prepared. The cut PVDF membrane was soaked in methanol for $10 \mathrm{sec}$ and transferred into the buffer solution with filter papers for soaking. A piece of sponge was placed on a splint, and two soaked filter papers were placed on the sponge and aligned accurately. The rinsed gel was placed on the top filter paper and air bubbles were removed with a glass tube. Thereafter, the PVDF membrane was placed on the gel aligning accurately, and 3 filter papers were placed on PVDF membrane. A piece of sponge was placed on the top filter paper, and the splint was clamped tightly when the air bubbles had been removed. One side of the gel was attached to the cathode and one side of filter membrane to the anode, and $100 \mathrm{~V}$ electrotransfer was conducted for $80 \mathrm{~min}$. Subsequently, the filter membrane was stained with ponceau at room temperature for $7 \mathrm{~min}$ to check whether protein transfer was fully completed. The PVDF membrane was placed into the BSA to block nonspecific binding, slowly shaken on the shaking table at room temperature for $1 \mathrm{~h}$, and removed. The PVDF membrane was placed into a hybridization bag containing $10 \mathrm{ml}$ Beclin 1 primary antibody $(1: 1,000)$, NeuN primary antibody $(1: 5,000)$, active caspase- 3 primary antibody (rabbit anti-rat antibody; 1:200; cat. no. ab2302; Abcam), and $\beta$-actin primary antibody (rabbit anti-rat antibody; 1:2,000; cat. no. ab8227; Abcam), diluted with the blocking solution, sealed, and slowly shaken on the shaking table at $4^{\circ} \mathrm{C}$ overnight. Following discarding of the blocking solution containing primary antibody, the PVDF membrane was placed into a hybridization bag containing $10 \mathrm{ml}$ horseradish peroxidase-labeled secondary antibody (goat anti-rabbit IgG 1:5,000; cat. no. zb-2301; OriGene Technologies, Inc., for the PVDF membrane incubated with Beclin 1 antibody, caspase- 3 antibody, and $\beta$-actin antibody; goat anti-mouse IgG 1:5,000; zb-2305; OriGene Technologies, Inc., for NeuN antibody) diluted with the blocking solution, sealed, and slowly shaken on the shaking table at room temperature for $1 \mathrm{~h}$. Following discarding of the blocking solution containing secondary antibody, the PVDF membrane was rinsed with Tris-buffered saline and Tween-20 (TBST) for $15 \mathrm{~min}$ four times. Solution A and solution $\mathrm{B}$ of the enhanced chemiluminescence (ECL) reagents (Santa Cruz Biotechnology, Inc., Dallas, TX, USA) were mixed 1:1 in a dark room (as calculated by $0.125 \mathrm{ml}$ ECL mixture/ $1 \mathrm{~cm}^{2}$ membrane). The PVDF membrane was gently dried with filter paper and placed on a fresh-keeping film with the side containing protein facing upward. ECL mixture was evenly added onto the PVDF membrane to react for $1 \mathrm{~min}$, and the PVDF membrane was lifted, dried gently with a filter paper and covered with the fresh-keeping film. Protein bands were scanned using Chemi Imager 5500 v2.03 software (ProteinSimple, San Jose, CA, USA), and the results were analyzed using a computerized image analysis system (FluorChem 2.0, ProteinSimple; Bio-Techne, Minneapolis, MN, USA). $\beta$-actin was used as the internal reference for comparison among groups. A higher relative gray scale indicated that the protein content was greater.

Reverse transcription-quantitative polymerase chain reaction (RT-qPCR) analysis. A total of $1 \mathrm{ml}$ TRIzol (Takara Biotechnology Co., Ltd., Dalian, China) was added into 1-2 g frozen tissue and homogenized. Subsequently, the tissue homogenate was treated with $0.2 \mathrm{ml}$ chloroform, heavily shaken, preserved at room temperature for $10 \mathrm{~min}$, and centrifuged at $4^{\circ} \mathrm{C}(12,000 \mathrm{x} \mathrm{g} ; 15 \mathrm{~min})$. The upper water phase was pipetted into an RNase Free Eppendorf tube, precooled $0.5 \mathrm{ml}$ isopropanol was added and mixed evenly, and the sample was preserved at room temperature for $10 \mathrm{~min}$, followed by centrifugation at $4^{\circ} \mathrm{C}(12,000 \mathrm{x} \mathrm{g} ; 10 \mathrm{~min})$. The supernatant was discarded, and the sediment was added with $1 \mathrm{ml}$ precooled $75 \%$ alcohol, mixed evenly and centrifuged at $4^{\circ} \mathrm{C}(7,500 \mathrm{x} \mathrm{g}$; $5 \mathrm{~min})$. The supernatant was discarded, and the sediment was dried at room temperature for $10-15 \mathrm{~min}$, added with $0.02 \mathrm{ml}$ RNase Free water for dissolution, and cryopreserved at $-80^{\circ} \mathrm{C}$ for use. The random primers and RNA template were denatured at $70^{\circ} \mathrm{C}$ for $5 \mathrm{~min}$, the reaction system was reverse transcribed using the Prime Script ${ }^{\mathrm{TM}}$ RT reagent kit with gDNA Eraser (Perfect Real Time) (cat. no. RR047A; Takara Bio, Inc.) at $37^{\circ} \mathrm{C}$ for $1.5 \mathrm{~h}$, inactivated at $70^{\circ} \mathrm{C}$ for $10 \mathrm{~min}$ and soaked in an ice bath for $5 \mathrm{~min}$, and cDNA was preserved at $-20^{\circ} \mathrm{C}$ for use. In order to control the sample loading errors during experimental procedures and the difference of amplification efficacy among various reaction tubes, GAPDH was set as internal reference, and the cycle was controlled in the linear phase of amplification reaction. The premiers were as follows: GAPDH forward primer, 5'-GCAAGTTCAACGGCACA-3' and reverse primer, 5'-CATTTGATGTTAGCGGGAT-3'; 
caspase-3 forward primer, 5'-GAAGAGTTGGAGCACTGTA GCAC-3' and reverse primer, 5'-TGGATCGTAGCACCCTGT CG-3'; and Beclin 1 forward primer, 5'-ACTGATGGCTGT AACGGTCTA-3' and reverse primer, 5'-CCAAGCAGATGG CACAGAGG-3'. SYBR ${ }^{\circledR}$ Premix Ex Taq ${ }^{\mathrm{TM}}$ (TliRNaseH Plus) (RR420A; Takara Bio, Inc.) was used for DNA amplification. The total volume of the mixture was $20 \mu \mathrm{l}$, and the reaction conditions were as follows: $95^{\circ} \mathrm{C}$ for $15 \mathrm{sec} ; 60^{\circ} \mathrm{C}$ for $1 \mathrm{~min}$; 45 cycles in total. The expression of target genes was calculated using the $2^{-\Delta \Delta \mathrm{Cq}}$ method (17).

Statistical analysis. SPSS 13.0 software (SPSS, Inc., Chicago, IL, USA) was used for the processing and statistical analysis of data. The data are presented as the mean \pm standard deviation. Statistical analysis was performed by two-way analysis of variance, followed by multiple comparison least significant difference (LSD) tests. $\mathrm{P}<0.05$ was considered to indicate a statistically significant difference.

\section{Results}

Morphological alterations. Cells were observed under a light microscope and it was demonstrated that in the control group, cells were arranged tightly and regularly, with a normal structure, had a morphology same as that of brain tissues from healthy rats, and appeared normal. In the model group, cell karyopyknosis and necrosis were observed at day 1; at day 3 , cells were unclear in hierarchy and structure, and periventricular white matter had a porous, malacotic structure; at day 7 periventricular white matter was loose and demonstrated net necrosis, and there was gliosis; at day 14, cerebral white matter and the corpus callosum became thinner, and fibers were disordered. However, no obvious gray matter nuclei and apparent cerebral cortex injury was observed by $\mathrm{H} \& \mathrm{E}$ staining (Fig. 1).

Decreased expression of NeuN. In the control group, NeuN mRNA expression was increased over the experimental time period. Compared with the control group, NeuN mRNA expression in the model group exhibited no significant change at day 1 , although it was significantly decreased and reached a trough at day 3 , followed by an increase at days 7 and 14; however, it remained lower compared with the respective control group $(\mathrm{P}<0.05$; Fig. $2 \mathrm{~A})$. In the model group, NeuN protein expression was decreased compared with the control group. The trend observed was consistent with the mRNA expression (Fig. 2B).

\section{Apoptosis of neurons}

Alterations in neuronal apoptosis detected by TUNEL. In the model group, the nuclei of TUNEL-positive cells were stained in a scattered spot pattern and shaped irregularly. Neuronal TUNEL-positive cells were notably increased and widely present in periventricular white matter, corpus callosum, hippocampus and cerebral cortex. A small number of positive cells were observed in the control group. At days 1 and 3 , the number of stained positive cells in the model group was markedly increased compared with the control group; at days 7 and 14, no difference was identified between the two groups (Fig. 3).

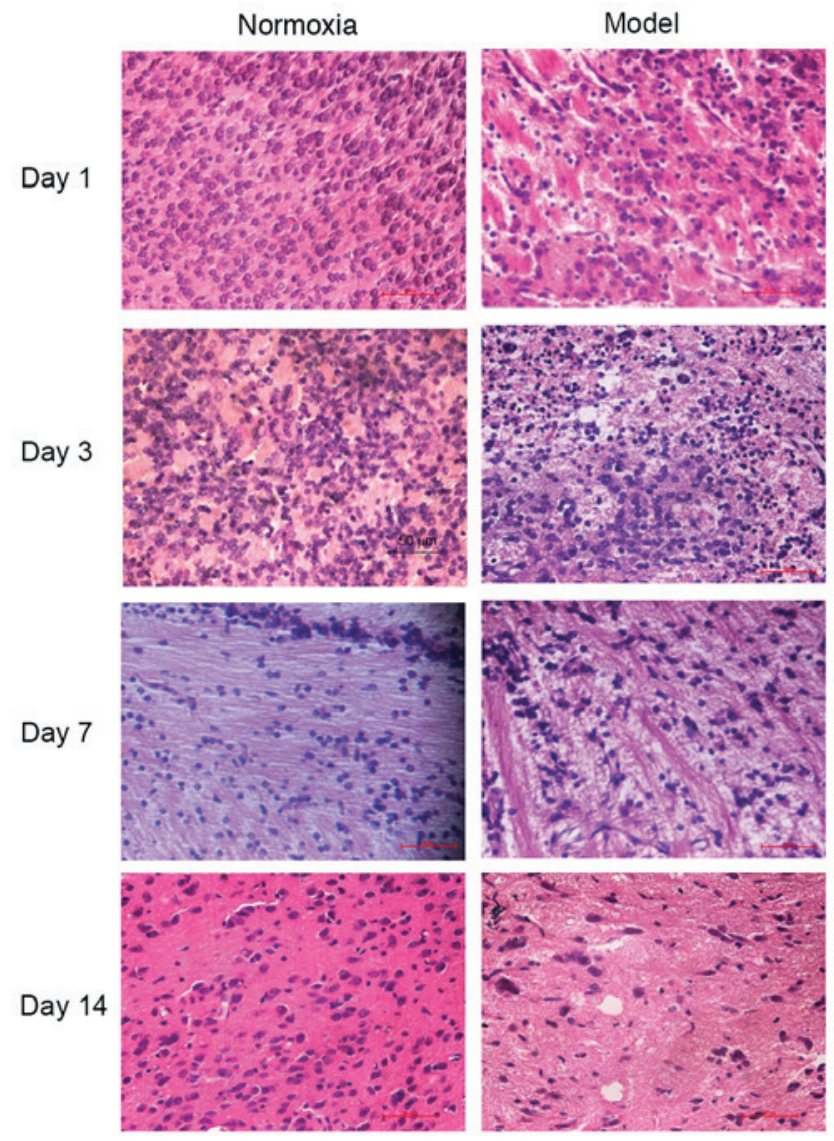

Figure 1. Alterations in brain tissues at different time-points following hypoxia-ischemia-induced injury observed by hematoxylin and eosin staining. Magnification, x400. The histomorphology was normal and cells were arranged tightly and regularly in the control group. In the model group cell karyopyknosis and necrosis were observed at day 1 . At day 3 , cells were unclear in hierarchy and structure, and periventricular white matter had a porous, malacotic structure, periventricular white matter became malacic, cellular necrosis was observed, and there was proliferation of gliocytes; at day 7, periventricular white matter was loose and demonstrated net necrosis, edema was decreased, and there was gliosis; at day 14, cerebral white matter and corpus callosum became thinner, fibers were disordered in a net or strip shape, and necrotic cells were decreased in number.

Increased expression of caspase-3. In the control group and model group, caspase- $3 \mathrm{mRNA}$ expression was significantly increased at day 3 compared with day $1(\mathrm{P}<0.01)$, although it was decreased at days 7 and 14 compared with day 1 . At days 1 , 3 and 7, caspase-3 mRNA expression in the model group was increased compared with the control group $(\mathrm{P}<0.05)$; at day 14 , caspase-3 mRNA expression in the model group was increased compared with the control group, although the difference between the two groups was not statistically significant $(\mathrm{P}>0.05$; Fig. 4A). In the control group and the model group, cleaved caspase-3 protein expression was significantly increased at day 3 compared with day $1(\mathrm{P}<0.01)$, and significantly decreased at days 7 and 14 compared with day 1 . At all time-points, cleaved caspase-3 protein expression in the model group was greater when compared with the control group $(\mathrm{P}<0.05$; Fig. 4B).

\section{Neuronal autophagy}

Double-labeling immunofluorescence staining of Beclin 1 and NeuN. Beclin1 was expressed in the cytoplasm, while NeuN 
A

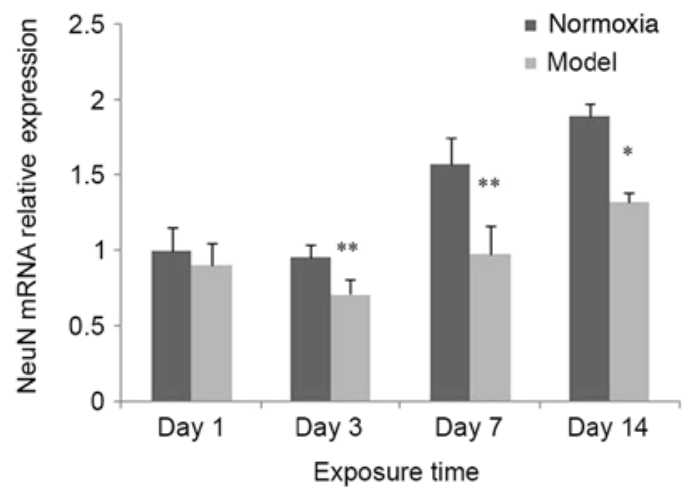

B
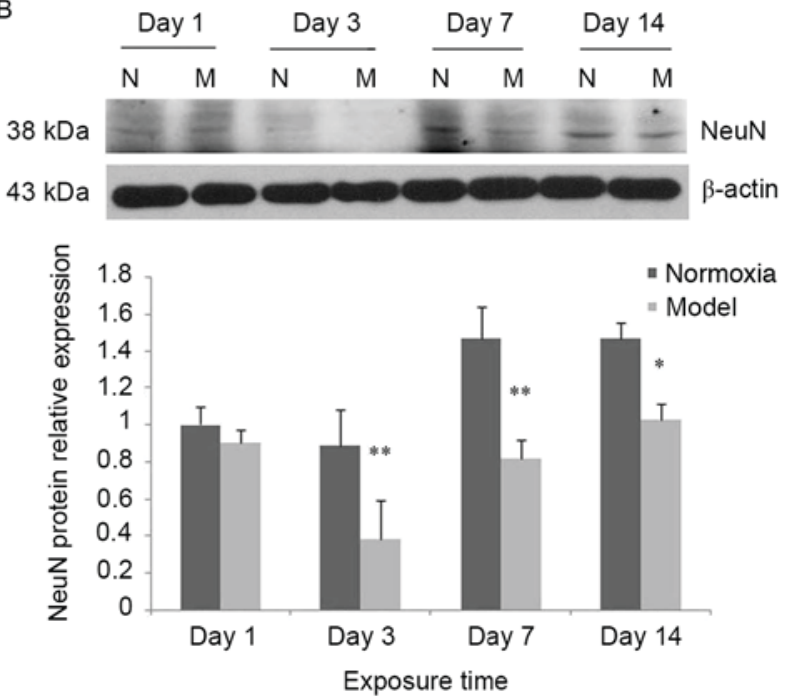

Figure 2. Alteration of NeuN expression at different time-points following hypoxia-ischemia-induced injury. (A) In the hypoxia-ischemia-induced injury model, NeuN mRNA expression in brain tissues was decreased. In the control group, NeuN protein expression was significantly increased at days 7 and 14 compared with days 1 and 3. Compared with the control group, NeuN mRNA expression in the model group was not significantly decreased on day 1 , although it was markedly decreased and reached a trough at day 3, and remained decreased at days 7 and 14; in the model group, NeuN mRNA expression at days 7 and 14 was increased compared with day 3. (B) In the hypoxia-ischemia-induced injury model, NeuN protein expression in brain tissues was decreased. In the control group, NeuN protein expression was significantly increased at days 7 and 14 compared with days 1 and 3 . Compared with the control group, NeuN protein expression in the model group was the model group was not significantly decreased on day 1 , although it was markedly decreased and reached a trough at day 3, and remained decreased at days 7 and 14. In the model group, NeuN protein expression at days 7 and 14 was markedly increased compared with day 3 . Data were obtained by densitometry and were normalized using $\beta$-actin as a loading control. Values are expressed as relative optical density and are presented as the mean \pm standard deviation. For each column, $\mathrm{n}=3$. ${ }^{*} \mathrm{P}<0.05,{ }^{* *} \mathrm{P}<0.01$ vs. thenormoxia group. N, normoxia; M, model; NeuN, neuronal nuclei.

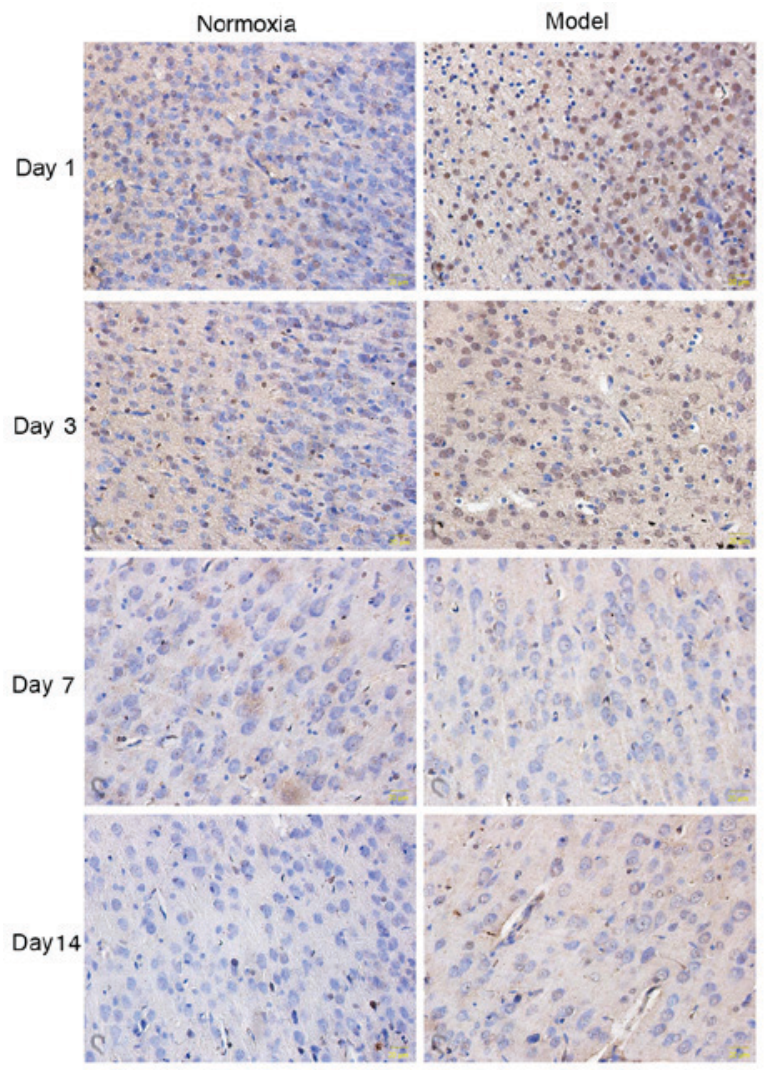

Figure 3. Alterations in terminal deoxynucleotidyl transferase dUTP nick end labeling assay results of brain tissues following hypoxia-ischemia-induced injury. Magnification, x500. In the control group, positive cells were observed and gradually decreased at days 1 and 3; no positive cells were observed at days 7 and 14. In the model group, positive cells were significantly increased compared with the control group at days 1 and 3; positive expression was rarely observed at days 7 and 14 . was primarily expressed in the nuclei, exhibiting limited expression in the cytoplasm. At day 7, cells were arranged regularly in the control group and irregularly in the model group; the co-expression of Beclin 1 and NeuN in the same cells was observed in the two groups, and the number of cells with such co-expression was increased in the model group compared with the control group (Fig. 5).

Increased expression of Beclin 1. In the control group, Beclin 1 mRNA expression was significantly increased at days 7 and 14 compared with days 1 and $3(\mathrm{P}<0.05)$. Compared with the control group, Beclin 1 mRNA expression in the model group was significantly increased at days 1,3 and 7 ( $\mathrm{P}<0.01$; Fig. 6A). In the model group, Beclin 1 protein expression was increased compared with the control group. The trend was consistent with the mRNA expression (Fig. 6B).

\section{Discussion}

Perinatal brain injury, one of the most common diseases in neonates and, particularly, premature neonates, may lead to altered development of the neonatal nervous system and result in varying degrees of sequelae. The most frequently reported manifestation is PVL (local or diffuse), which is the primary cause of cerebral palsy and may induce cognitive dysfunction, motor dysfunction or visual impairment $(18,19)$. PVL is most frequently observed in premature infants and maybe caused by a number of factors, including perinatal infection and asphyxia. Previous studies of PVL have focused on oligodendrocyte involvement, myelinization disorders and microglial cell activation. OPCs are the primary targets organ for PVL $(20,21)$. In general, PVL occurs in premature infants at a gestational age 
A

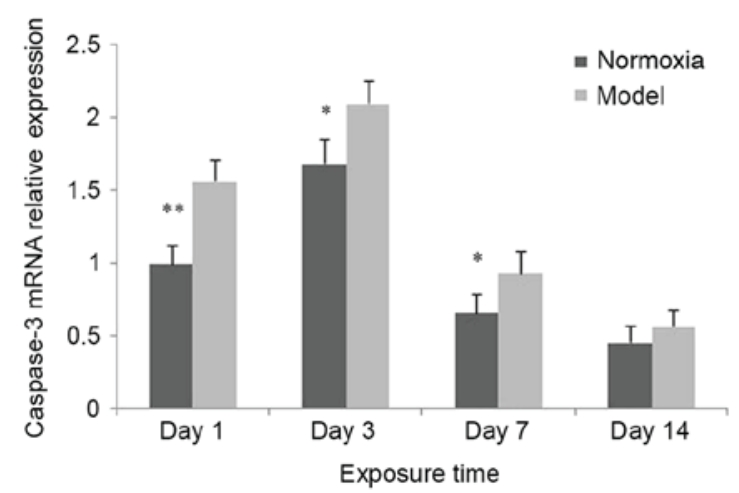

B
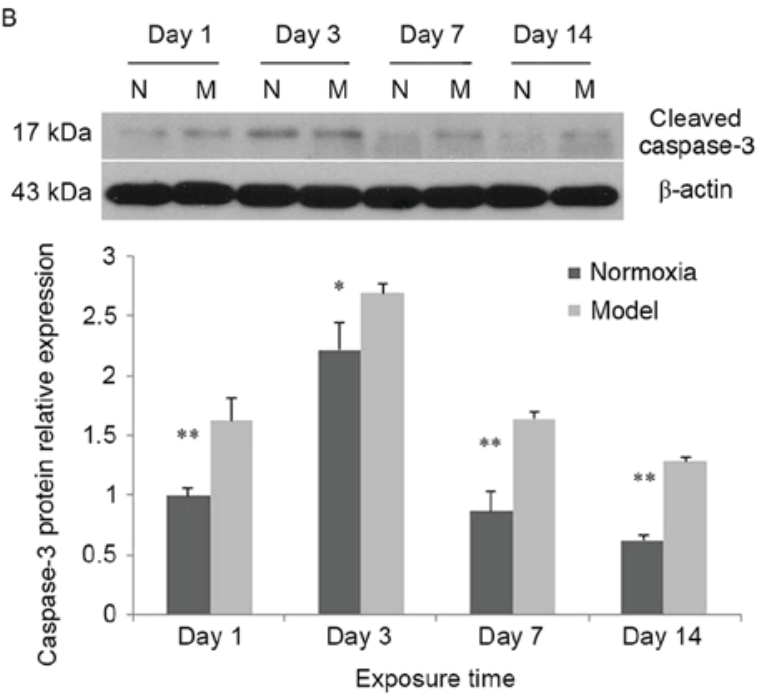

Figure 4. Alterations in caspase-3 expression at different time-points following hypoxia-ischemia-induced injury. (A) In the hypoxia-ischemia-induced injury model, caspase-3 mRNA expression in brain tissues was increased. In the control and model groups, caspase- 3 mRNA expression was significantly increased at day 3 compared with day 1 , and decreased at days 7 and 14 compared with day 1 . At days 1,3 and 7, caspase- 3 mRNA expression in the model group was increased compared with the control group; at day 14, caspase-3 mRNA expression in the model group was not significantly increased compared with the control group. (B) In the hypoxia-ischemia-induced injury model, cleaved caspase-3 protein expression in brain tissues was increased. In the control and model groups, cleaved caspase- 3 protein expression was significantly increased at day 3 compared with day 1, and decreased at days 7 and 14 compared with day 1 . At all time-points, cleaved caspase-3 protein expression in the model group was increased compared with the control group. Values are expressed as relative optical density and are presented as the mean \pm standard deviation. For each column, $\mathrm{n}=3$. ${ }^{*} \mathrm{P}<0.05,{ }^{* *} \mathrm{P}<0.01$ vs. the normoxia group. $\mathrm{N}$, normoxia $\mathrm{M}$, model.

of 23-32 weeks; OPCs account for $\sim 90 \%$ of the total number of oligodendrocytes in the cerebral white matter of these infants, although they are markedly decreased in $>32$-week infants, which is consistent with a reduction in the incidence rate of PVL. A number of previous studies have demonstrated the increased vulnerability of immature oligodendrocytes during a specific window $(22,23)$. Animal experiments have confirmed that, based on the maturation-dependent vulnerability of oligodendrocytes, OPCs are easily injured by glutamates, oxygen-derived free radicals and inflammatory cytokines, thus leading to apoptosis, necrosis and myelinization delay $(24,25)$. Hypoxia increases the phagotrophic and oxidative stress

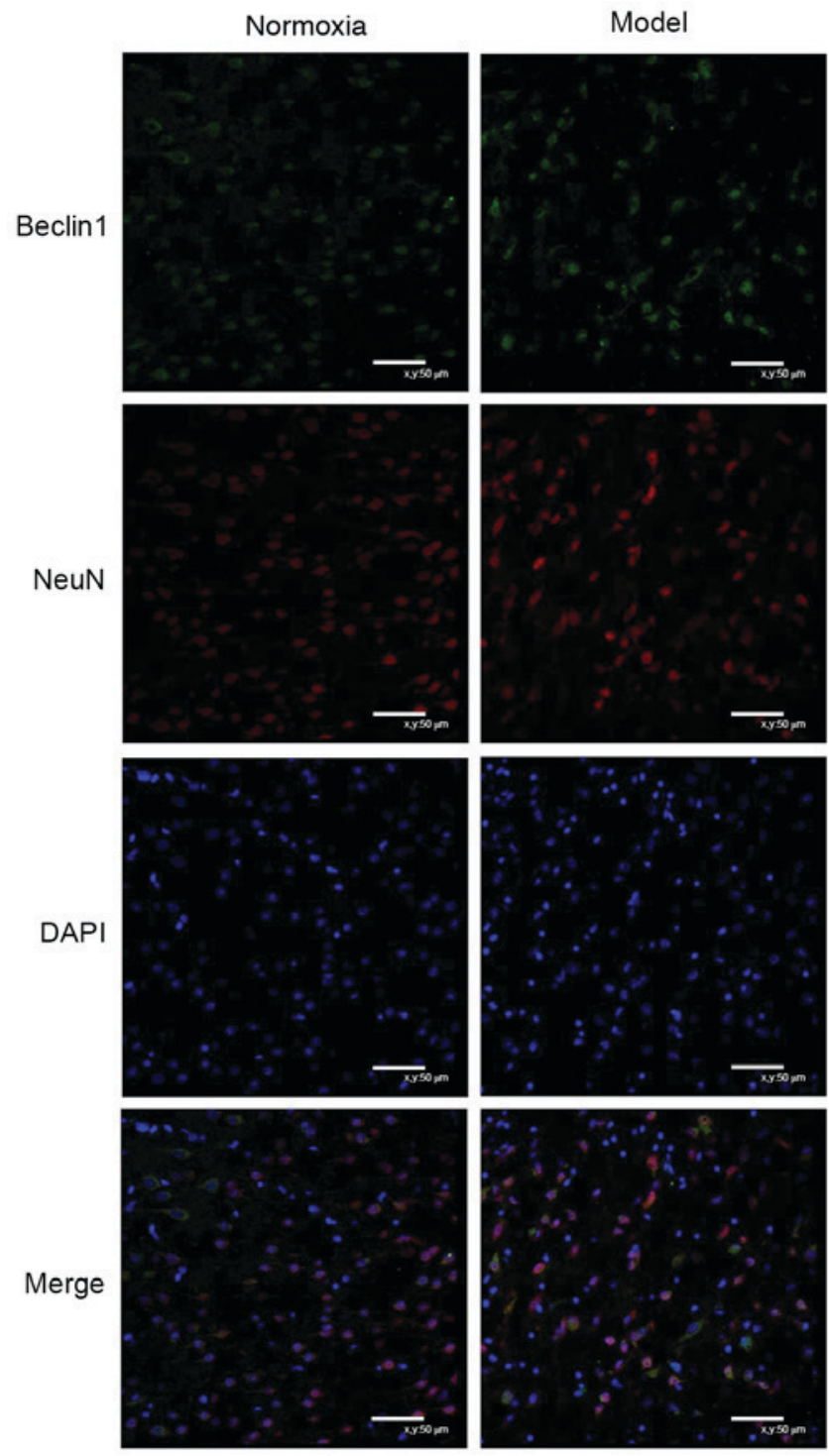

Figure 5. Alterations in Beclin 1 expression in brain tissues at day 7 following hypoxia-ischemia-induced injury. Magnification, x400. The positive co-expression of NeuN (red) and Beclin 1 (green) was observed in the same cells. Beclin1 was expressed in the cytoplasm, whereas NeuN was predominantly expressed in the nuclei. At day 7, cells were arranged regularly in the control group and irregularly in the model group; in the model group, certain cells were fragmented, and certain cells were necrotic with a disordered morphology. NeuN, neuronal nuclei.

injury-promoting functions of microglial cells through mediation of inflammatory cytokines, including $\gamma$-interferon, tumor necrosis factor- $\alpha$, interleukin-1 and lipopolysaccharide causing microglia cells to release excitatory glutamates $(26,27)$. Accordingly, the expression of $\alpha$-amino-3-hydroxy-5-methyl- 4 -isoxazolepropionic acid and N-methyl-D-aspartic acid receptors (NR1 and NR2A-D) has been observed to be increased in microglial cells (28). Activated microglial cells may induce the death of OPCs and astrocytes, which has been widely confirmed $(29,30)$.

However, neuronal injury has also been frequently observed in PVL as the understanding of PVL has been increasing. Volpe et al (14), first proposed the concept of EP, and they observed non-negligible neuronal injury among brain injuries in premature infants. Andiman et al (13), reported a 
A

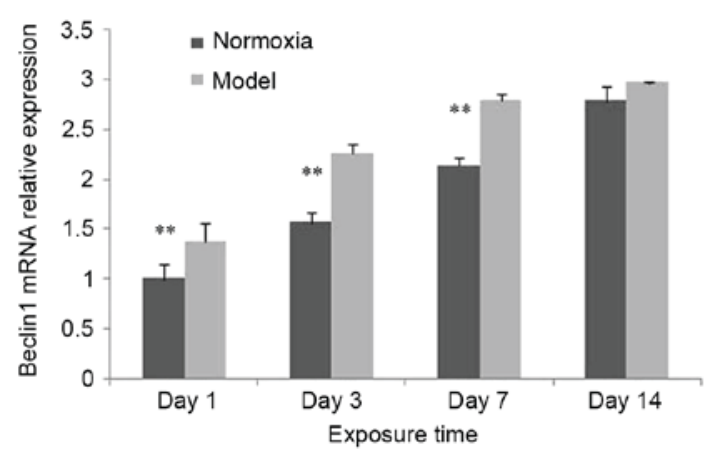

B
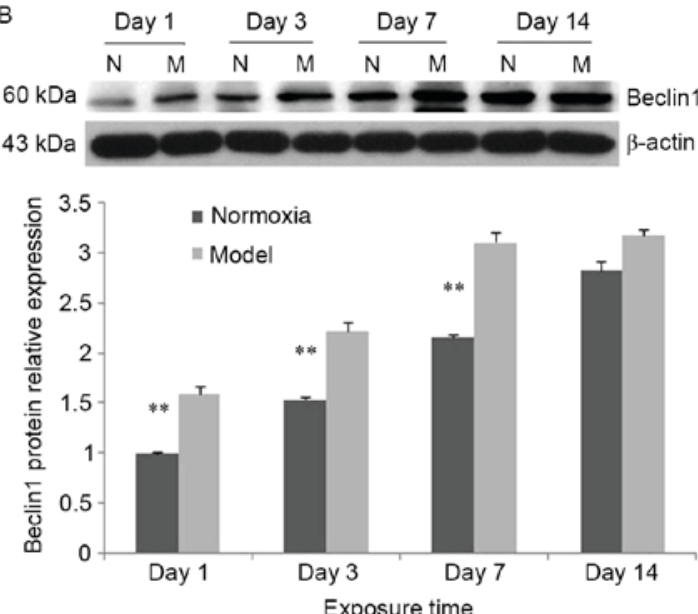

Figure 6. Alterations in Beclin 1 expression at different time points following hypoxia-ischemia-induced injury. (A) In the hypoxia-ischemia-induced injury model, Beclin 1 mRNA expression in brain tissues was increased. In the control and model groups, Beclin 1 mRNA expression was increased between days 1 and 14. Compared with the control group, Beclin $1 \mathrm{mRNA}$ expression in the model group was significantly increased at days 1, 3 and 7. (B) In the hypoxia-ischemia-induced injury model, Beclin $1 \mathrm{mRNA}$ expression in brain tissues was increased. In the control group and model group, Beclin $1 \mathrm{mRNA}$ expression was increased from day 1 to day 14. Compared with the control group, Beclin 1 protein expression in the model group was significantly increased at days 1,3 and 7 . Values are expressed as relative optical density and are presented as the mean \pm standard deviation. For each column, $\mathrm{n}=3$. ${ }^{*} \mathrm{P}<0.05,{ }^{* * *} \mathrm{P}<0.01$ vs. the normoxia group. N, normoxia; M, model.

$38 \%$ decrease in the density of pyramidal neurons in the fifth layer of the cerebral cortex of premature infants with PVL. In addition, neuropathologists have previously demonstrated that the time at which neurons in the germinative zone migrated towards the cerebral cortex via the periventricular white matter coincided with the time when periventricular WMI occurred, and the toxicities of inflammatory cytokines and excitatory amino acids may injure these migrating neurons while damaging periventricular white matter (31). Such neurons (for example, subplate neurons) may exhibit the same pathogenesis as OPCs in white matter (32), express a number of glutamate receptors, and demonstrate selective vulnerability similar to OPCs $(33,34)$. In the present study, neuronal injury in premature infants following hypoxia-ischemia was investigated using a hypoxia-ischemia-induced PVL model. The model was successfully established in a previous PVL study completed by the present research group (15). NeuN is a soluble nucleoprotein and a marker of mature neurons, and its molecular weight is $46-48 \mathrm{kDa}$. In the present study, NeuN expression was reduced and mature neurons were reduced in the model group, which indicated that the number of mature neurons was decreased in the rat model of hypoxia-ischemia-induced PVL; the presence of neuronal injury in PVL was confirmed in the animal models. NeuN expression reached a trough in the model group at day 3 , suggesting that neuronal injury was most severe at day 3 following hypoxic exposure. NeuN protein expression was increased at day 7 to exceed the level at day 1 ; however, it remained low compared with the level observed in the control group, which demonstrated that a certain repair mechanism to achieve neuronal regeneration or transformation following neuronal injury was induced by hypoxia in premature infants, although NeuN protein expression was not able to be recovered to the same level as prior to the injury. The trough of $\mathrm{NeuN}$ expression in the model group was observed at day 3 , perhaps due to the repair mechanism not having been initiated while tissue injury was ongoing. The present study further investigated the apoptosis and autophagy of injured neurons, in an attempt to elucidate the injury and repair mechanisms.

The following types of cell death have been recognized: Necrosis, apoptosis (type I apoptosis) and autophagic apoptosis (type II apoptosis) (35). Necrosis is a type of non-apoptotic cell death caused by external injury, and its morphological characteristics are different from those of apoptosis; generally, necrosis is accompanied by inflammation (36). Caspase-3 is a member of the caspase family and an important protein to detect in apoptosis, as there are caspase-3-dependent and caspase-3-independent forms of apoptosis. Cleaved caspase- 3 is an active form of sliced caspase- 3 , and its protein expression elevation may indicate apoptosis increase (37). In the present study, caspase-3 expression was increased and reached a peak at day 3 (when NeuN expression reached at rough) in the model group, and thereafter it was decreased (mean while NeuN expression was increased). Therefore, it may be inferred that caspase-3-dependent apoptosis may be an important cause of neuronal injury. A number of studies have demonstrated that hypoxia may lead to an increase in neuronal apoptosis and result in brain injury (38-40). The peak expression of caspase- 3 in the control group was additionally observed at day 3 (6 days following birth). There are previous studies investigating hypoxia-ischemia-induced brain injury in P5-7 rats (equal to full-term or nearly full-term human infants) $(41,42)$. Therefore, it was considered that P5-7 maybe a window for neuronal injury and P5-7 rats may demonstrate the most marked apoptosis and the least tolerance to hypoxia. The TUNEL assay results in the present study further confirmed that neuronal apoptosis in the cerebral cortex was increased in the hypoxia-ischemia-induced PVL model. The results of the present study demonstrated that in the hypoxia-ischemia-induced PVL model, in addition to injury to oligodendrocytes, there was a decrease in the 
number of neurons and an increase in neuronal apoptosis, which validates the hypothesis that neuronal apoptosis is an important cause of neuronal injury in this model.

Autophagic programmed cell death is embodied by the appearance of numerous vacuolar structures, encapsulating the cytoplasm and organelles within the cytoplasm, and the degradation of their contents by lysosomes. In autophagic programmed cell death, intermediate filaments and microfilaments are redistributed, although not degraded, and actin remains in a polymeric form, so the cytoskeletal system is well-maintained. Conversely, in apoptotic programmed cell death, the depolymerization of actin and the degradation of intermediate filaments occur early on, and the cytoskeletal system is consequently damaged. Autophagy exerts an important role in the growth and development of cells, and the occurrence of diseases. A number of studies have reported that autophagy and apoptosis may antagonize or promote one another in certain cases, and they may occur successively or co-exist in the same cells $(35,43-45)$. Beclin1 was the first autophagy-associated gene identified in mammals, and the Beclin 1 protein is able to bind to type III phosphatidylinositol 3-kinase (PI3K) to regulate autophagy (46). The results of the present study demonstrated that Beclin 1 expression was gradually increased in the model group, with a trend coincident to the increase of $\mathrm{NeuN}$ expression and opposite to the decrease of caspase-3 expression. Therefore, it was hypothesized that autophagy may be involved in the inhibition of apoptosis and even the repair process of neuronal injury, which requires validation in subsequent experiments. Balduini et al (38) suggested that autophagy may be part of a pro-survival signal containing the PI3K-Rac- $\alpha$ serine/threonine protein kinase-protein kinase mTOR axis, and that its activation mechanisms included drug effects, infection and hypoxia-ischemia. Carloni et al (47) demonstrated that rapamycin administration prior to hypoxia-ischemia markedly increased the expression of Beclin 1 and microtubule-associated proteins $1 \mathrm{~A} / 1 \mathrm{~B}$ light chain $3 \mathrm{~B}$ (autophagy-associated proteins), and decreased neuronal injury. These previous results indicated that facilitating autophagy prior to hypoxia-ischemia may have a certain protective effect on neurons, while interrupting autophagy may inhibit such protection. It was previously reported that blocking autophagy at $3 \mathrm{~h}$ post-ischemia/reperfusion had a neuroprotective role (48). Therefore, autophagy may be used as a target for the protective treatment of the nervous system. This opposite result demonstrates the double role of autophagy: Autophagy is protective in the early stage sand harmful in the late stages of nerve degeneration, which depends on the time of drug administration. Therefore, autophagy has a double effect on cells and neurons: In hypoxia-ischemia-induced injury, it may protect cells and prevent cell death, or may become one of the factors causing cell death, specifically depending on different phases of disease progression, alterations to the pericellular environment, and different intervention measures. The present study demonstrated that Beclin 1 was expressed in neurons, and that Beclin 1 expression was increased in the model group, close to the level of the control group at day 14 following hypoxia-induced injury; the time of the Beclin 1 expression increase coincided with the time window of repair following neuronal injury. Therefore, it may be inferred that cellular autophagy may exert a protective effect on neurons in the hypoxia-ischemia-induced PVL rat model, which requires confirmation in further experiments.

In conclusion, there are alterations to oligodendrocytes and neurons in a hypoxia-ischemia-induced PVL model. In the model group, the trough of neuronal cell expression was observed at the time-point when cellular apoptosis was in the most active state, which proves that neuronal apoptosis is an important cause of neuronal injury. Neuronal autophagy is additionally involved in this pathological process, although it is increased at the later stages of injury. Cellular autophagy may exhibit protective effect in neurons, although its specific role in this process has not been confirmed. The present study may promote a novel target for the treatment of PVL.

\section{Acknowledgements}

We gratefully acknowledge Professors Dongyan Liu and Guifeng Zhao for invaluable help during the study. We would like to thank the Center Laboratory and Department of Animal of Shengjing Hospital of China Medical University for expert assistance.

\section{Funding}

Not applicable.

\section{Availability of data and materials}

The analyzed data sets generated during the study are available from the corresponding author on reasonable request.

\section{Authors' contributions}

LQ: Conceptualization of the study, performance of assays, data curation, formal analysis, investigation, validation, writing at the original draft and review and editing stage. JF: Conceptualization of the study, data curation, performance of assays, validation and writing at the review and editing stage. $\mathrm{XX}$ : Conceptualization of the study, data curation, performance of assays, validation and supervision. YS: Conceptualization of the study and performance of assays. LY: Conceptualization of the study and performance of assays. WH: Data curation and formal analysis. JL: Data curation and formal analysis. DZ: Investigation. NL: Investigation. XT: Formal analysis and software operation. YD: Performance of assays and writing of the original draft. YP: Performance of assays and writing of the original draft.

\section{Ethics approval and consent to participate}

Ethical approval for the present study was provided by Shengjing Hospital of China Medical University Ethics Committee (Shenyang, China).

\section{Consent for publication}

Not applicable. 


\section{Competing interests}

All authors declared that they have no conflict of interest with regard to this study.

\section{References}

1. Deng W, Pleasure $\mathbf{J}$ and Pleasure D: Progress in periventricular leukomalacia. Arch Neuro 165: 1291-1295, 2008.

2. Hamilton BE, Miniño AM, Martin JA, Kochanek KD, Strobino DM and Guyer B: Annual summary of vital statistics: 2005. Pediatrics 119: 345-360, 2007.

3. Volpe JJ: Cerebral white matter injury of the premature infant-more commonthan you think. Pediatrics 112: 176-180, 2003.

4. Dyet LE, Kennea N, Counsell SJ, Maalouf EF, Ajayi-Obe M, Duggan PJ, Harrison M, Allsop JM, Hajnal J, Herlihy AH, et al Natural history of brain lesions in extremelypreterm infants studied with serial magnetic resonance imaging from birth and neurodevelopmental assessment. Pediatrics 118: 536-548, 2006.

5. Hack M, Taylor HG, Drotar D, Schluchter M, Cartar L, Wilson-Costello D, Klein N, Friedman H, Mercuri-Minich N and Morrow M: Poor predictive validity of the bayley scales of infant development for cognitive function of extremely low birth weight children at school age. Pediatrics 116: 333-341, 2005.

6. Wilson-Costello D, Friedman H, Minich N, Siner B, Taylor G, Schluchter $M$ and Hack M: Improved neurodevelopmental outcomes for extremely low birth weight infants in 2000-2002. Pediatrics 119: 37-45, 2007.

7. Leviton A, Dammann O and Durum SK: The adaptive immune response in neonatal cerebral white matter damage. Ann Neurol 58: 821-828, 2005.

8. Dommergues MA, Plaisant F, Verney C and Gressens P: Early microglial activation following neonatal excitotoxic brain damage in mice: A potential target for neuroprotection. Neuroscience 121: 619-628, 2003.

9. Tahraoui SL, Marret S, Bodénant C, Leroux P, Dommergues MA Evrard P and Gressens P: Central role of microglia in neonatal excitotoxic lesions of the murine periventricular white matter. Brain Pathol 11: 56-71, 2001.

10. Back SA: Brain injury in the preterm infant: New horizons for pathogenesis and prevention. Pediatr Neurol 53: 185-192, 2015.

11. Zonouzi M, Scafidi J, Li P, McEllin B, Edwards J, Dupree JL, Harvey L, Sun D, Hübner CA, Cull-Candy SG, et al: GABAergic regulation of cerebellar NG2 cell development is altered in perinatal white matter injury. Nat Neurosci 18: 674-682, 2015.

12. Sarnat HB, Philippart M, Flores-Sarnat L and Wei XC: Timing in neural maturation: Arrest, delay, precociousness and temporal determination of malformations. PediatrNeurol 52: 473-486, 2015.

13. Andiman SE, Haynes RL, Trachtenberg FL, Billiards SS, Folkerth RD, Volpe JJ and Kinney HC: The cerebral cortex overlying periventricular leukomalacia: Analysis of pyramidal neurons. Brain Pathol 20: 803-814, 2010.

14. Volpe JJ: Encephalopathy of prematurity includes neuronal abnormalities. Pediatrics 116: 221-225, 2005.

15. Cheng T, Xue X and Fu J: Effect of OLIG1 on the development of oligodentrocytes and myelination in a neonal rat PVL model induced by hypoxia-ischemia. Mol Med Rep 11: 2379-2386, 2015.

16. Mizuno K, Hida $\mathrm{H}$, Masuda $T$, Nishino $H$ and Togari $H$ Pretreatment with low doses of erythropoietin ameliorates brain damage in periventricular leukomalacia by targeting late oligodendrocyte progenitors: A rat model. Neonatology 94: 255-266, 2008.

17. Livak KJ and Schmittgen TD: Analysis of relative gene expression data using real-time quantitative PCR and the 2(-Delta Delta C(T)) method. Methods 25: 402-408, 2001.

18. Marret S, Marchand-Martin L, Picaud JC, Hascoët JM, Arnaud C, Rozé JC, Truffert P, Larroque B, Kaminski M and Ancel PY; EPIPAGE Study Group: Brain injury in very preterm children and neurosensory and cognitive disabilities during childhood: The EPIPAGE cohort study. PLoS One 8: e62683, 2013.

19. Volpe JJ: Brain injury in premature infants: A complex amalgam of destructive and developmental disturbances. Lancet Neurol 8: 110-124, 2009.

20. Jiang P, Chen C, Liu XB, Pleasure DE, Liu Y and Deng W: Human iPSC-derived immature astroglia promote oligodendrogenesis by increasing TIMP-1 Secretion. Cell Rep 15: 1303-1315, 2016.
21. Jantzie LL, Talos DM, Jackson MC, Park HK, Graham DA, Lechpammer M, Folkerth RD, Volpe JJ and Jensen FE: Developmental expression of N-methyl-D-aspartate (NMDA) receptor subunits in human white and gray matter: Potential mechanism of increased vulnerability in the immature brain. Cereb Cortex 25: 482-495, 2015

22. Haynes RL, Baud O, Li J, Kinney HC, Volpe JJ and Folkerth DR: Oxidative and nitrative injury in periventricular leukomalacia: A review. Brain Pathol 15: 225-233, 2005.

23. Back SA and Rivkees SA: Emerging concepts in periventricular white matter injury. Semin Perinatol 28: 405-414, 2004.

24. Craig A, Ling Luo N, Beardsley DJ, Wingate-Pearse N, Walker DW, Hohimer AR and Back SA: Quantitative analysis of perinatal rodent oligodendrocyte lineage progression and its correlation with human. Exp Neurol 181: 231-240, 2003

25. Emery B: Transcriptional and post-transcriptional control of CNS myelination. Curr Opin Neurobiol 20: 601-607, 2010.

26. Liu Y, Silverstein FS, Skoff R and Barks JD: Hypoxic-ischemic oligodendroglial injury in neonatal rat brain. Pediatr Res 51: 25-33, 2002.

27. Segovia KN, McClure M, Moravec M, Luo NL, Wan Y, Gong X, Riddle A, Craig A, Struve J, Sherman LS and Back SA: Arrested oligodendrocyte lineage maturation in chronicperinatal white matter injury. Ann Neurol 63: 520-530, 2008.

28. Manning SM, Boll G, Fitzgerald E, Selip DB, Volpe JJ and Jensen FE: The clinically available NMDA receptor antagonist, memantine, exhibits relative safety in the developing rat brain. Int J Dev Neurosci 29: 767-773, 2011.

29. Xapelli S, Bernardino L, Ferreira R, Grade S, Silva AP, Salgado JR, Cavadas C, Grouzmann E, Poulsen FR, Jakobsen B, et al: Interaction between neuropeptide Y (NPY) and brain-derived neurotrophic factor in NPY-mediated neuroprotection against excitotoxicity: A role for microglia. Eur J Neurosci 27: 2089-2102, 2008

30. Domercq M, Sánchez-Gómez MV, Sherwin C, Etxebarria E, Fern R and Matute C: System xc- and glutamate transporter inhibition mediates microglial toxicity to oligodendrocytes. J Immunol 178: 6549-6556, 2007.

31. Leviton A and Gressens P: Neuronal damage accompanies perinatal white-matter damage. Trends Neurosci 30: 473-478, 2007.

32. Haynes RL, Xu G, Folkerth RD, Trachtenberg FL, Volpe JJ and Kinney HC: Potential neuronal repair in cerebral white matter injury in the human neonate. Pediatr Res 69: 62-67, 2011.

33. Talos DM, Fishman RE, Park H, Folkerth RD, Follett PL, Volpe JJ and Jensen FE: Developmental regulation of alpha-amino-3-h ydroxy-5-methyl-4-isoxazole-propionic acid receptor subunit expression in forebrain and relationship to regional susceptibility to hypoxic/ischemic injury. I. Rodent cerebral white matter and cortex. J Comp Neurol 497: 42-60, 2006.

34. Zubiaurre-Elorza L, Soria-Pastor S, Junque C, Segarra D, Bargalló N, Mayolas N, Romano-Berindoague C and Macaya A: Gray matter volume decrements in preterm children with periventricular leukomalacia. Pediatr Res 69: 554-560, 2011.

35. Lockshin RA and Zakeri Z: Apoptosis, autophagy, and more. Int J Biochem Cell Biol 36: 2405-2019, 2004.

36. Natoli G, Costanzo A, Guido F, Moretti F and Levrero M: Apoptotic, non-apoptotic, and anti-apoptotic pathways of tumor necrosis factor signalling. Biochem Pharmacol 56: 915-920, 1998.

37. Budd RC: Activation-induced cell death. Curr Opin Immunol 13: 356-362, 2001.

38. Balduini W, Carloni S and Buonocore G: Autophagy in hypoxia-ischemia induced brain injury. J Matern Fetal Neonatal Med 25 (Suppl 1): S30-S34, 2012.

39. Barteczek P, Li L, Ernst AS, Böhler LI, Marti HH and Kunze R: Neuronal HIF-1 $\alpha$ and HIF- $2 \alpha$ deficiency improves neuronal survival and sensorimotor function in the early acute phase after ischemic stroke. J Cereb Blood Flow Metab 37: 291-306, 2017.

40. Xiang Q, Zhou WY, Hu WX, Wen Z, He D, Wu XM, Wei HP, Wang WD and Hu GZ: Neuroprotective effects of Rhizoma Dioscoreae polysaccharides against neuronal apoptosis induced by in vitro hypoxia. ExpTher Med 10: 2063-2070, 2015.

41. Olgun Y, Kırkım G, Kolatan E, Kıray M, Bağrıyanık A, Şerbetçioğlu B, Yılmaz O, Gökmen N, Ellidokuz H, Kumral A and Sütay S: Otoprotective effect of recombinant erythropoietin in a model of newborn hypoxic-ischemic encephalopathy. Int J Pediatr Otorhinolaryngol 77: 739-746, 2013. 
42. Pimentel-Coelho PM, Magalhães ES, Lopes LM, deAzevedoL C, Santiago MF and Mendez-Otero R: Human cord blood transplantation in a neonatal rat model of hypoxic-ischemic brain damage: Functional outcome related to neuroprotection in the striatum. Stem Cells Dev 19: 351-358, 2010.

43. Reggiori F: Membrane origin for autophagy. Curr Top Dev Biol 74: 1-30, 2006.

44. Tsujimoto Y and Shimizu S: Another way to die: Autophagic programmed cell death. Cell Death Differ 12 (Suppl 2): S1528-S1534, 2005.

45. Tang JF, Wen Q, Sun J, Zhang WM and Zhu HL: Advances in the researches on the biological activities and inhibitors of phosphatidylinositol 3-kinase. Anticancer Agents Med Chem 14 673-687, 2014.

46. Gallagher LE, Williamson LE and Chan EY: Advances in autophagy regulatory mechanisms. Cells 5: E24, 2016.
47. Carloni S, Girelli S, Scopa C, Buonocore G, Longini M and Balduini W: Activation of autophagy and Akt/CREB signaling play an equivalent role in the neuroprotective efect of rapamycin in neonatal hypoxia-ischemia. Autophagy 6: 366-377, 2010.

48. Shi R, Weng J, Zhao L, Li XM, Gao TM and Kong J: Excessive autophagy contributes to neuron death in cerebral ischemia. CNS Neurosci Ther 18: 250-260, 2012.

(c) (i) $\ominus$ This work is licensed under a Creative Commons Attribution-NonCommercial-NoDerivatives 4.0 International (CC BY-NC-ND 4.0) License. 